\title{
1. Digital innovation: towards a transdisciplinary perspective
}

\author{
Satish Nambisan, Kalle Lyytinen and Youngjin Yoo
}

\section{INTRODUCTION}

The emergence of a wide range of digital technologies and the ever-expanding digital infrastructures they comprise-including mobile and wearable computing, social media, blockchain, virtual and augmented reality, cloud computing services, data analytics and machine learning, robotics, Internet of Things, and 3D printing - is radically reshaping the nature, process, and outcomes of innovation. Digital innovation can be generally defined as "the creation of (and consequent change in) market offerings, business processes, or models that result from the use of digital technology" (Nambisan, Lyytinen, Majchrzak, \& Song, 2017, p. 224). It is driven by the efforts of "carrying out of new combination of digital and physical components" to produce new market offerings (Yoo, Henfridsson, \& Lyytinen, 2010a, p. 725). It involves increasingly amorphous agency as well as vaguely determined initial outcomes, resulting from a continuous flow of augmenting, expanding, and integrating new digital technologies into infrastructure and broader ecosystems (Eaton, Elaluf-Calderwood, Sørensen, \& Yoo, 2011).

Due to the specific nature and ontology of the digital (Faulkner \& Runde, 2019; Kallinikos, Aaltonen, \& Marton, 2013; Yoo et al., 2010a), digital technologies have fueled unprecedented forms of innovation that cut across traditional industry/sectoral boundaries, embrace networks, ecosystems, and communities, while accelerating ideation, development, and evolution of associated often radical products and services. The now common examples of Uber, Airbnb, Tesla, or new Fintech ecosystems make the point. Similarly, the ongoing infusion of digital capabilities and resulting platformization of physical products such as cars allows for increasingly fluid, radical, and dynamic value propositions that reshape industry structures. Digital "transformation" is now omnipresent and cuts across organizations in all sectors - new and old, large and small, public and private - and poses considerable, untried, and novel challenges to their innovation agenda, strategies, and practices.

Due to its encompassing nature and potentially deep effects across levels, settings, technologies, and organizational functions, digital innovation is now a transdisciplinary topic. It invites ideas and insights from a wide range of social science and management fields as it questions many paradigmatic assumptions held in these fields including among others economics, psychology, sociology, communication, marketing, entrepreneurship, strategy, organizational behavior, finance, design, cognitive science, technology management, information systems, health/medicine, public policy, and social welfare. At the same time, it calls for closer collaboration with computer science, data analytics, and software engineering scholars to understand the nature, architecture, and features of emerging technologies and their capabilities and to evaluate more faithfully their potential effects. As the fusion between digital and physical expands its scope, digital innovations fuel and are fueled by previously remote fields such as 
various fields of engineering (mechanical, material, and chemical), science (physics, chemistry, and biology), and medicine. And, finally as the impact of digital innovations penetrates every aspect of human lives beyond organized economic activities, it calls for collaboration with scholars in fields such as humanities, law, education, and journalism. Such a broadened perspective towards digital innovation research will emphasize not just social, organizational, and management scholarship that typically are concerned about innovation research, but also all the other fields/disciplines mentioned above, as we seek to advance a more realistic and coherent understanding of the myriad implications of digital innovation on economic, social, behavioral, political, legal, technological, scientific, moral, and ethical, and scientific issues.

This onslaught of new digital technologies and the subsequent call for reassessment and development of new research directions has not gone unnoticed in many pockets of management and organizational scholarship. To wit, we have recently witnessed an explosion of theoretical, empirical, and practical inquiries or calls for such inquiries to study the peculiarities and unique facets of digital innovation - its nature, process, and consequences - across all fields of management and organizational theory. For instance, over the past few years, we have noticed a significant shift in how the topic of digital innovation is recognized and discussed at the Annual Academy of Management Meetings. About a decade ago any topic related to digital innovation would only have been discussed in the divisions directly dealing with information systems and technologies (OCIS) and technology management (TIM). A few years later strategy (STR) and entrepreneurship (ENT) divisions also started to have panels on digital technologies and platforms and on whether we need to change our theories in these areas due to the digital phenomena. In 2019, nearly all divisions from cognition and management theory, to human resources and organizational development had sessions dealing with "digital x." Similarly, in entrepreneurship new specialties such as "digital entrepreneurship" and in information systems new scholarly communities around "digital innovation" have emerged. Similar observations can be made in the domain of marketing (digital marketing), international business (digital globalization), and other social science areas (such as digital journalism, digital law, digital geographies) as well natural science areas (computational chemistry, computational biology, computational physics).

At the same time, there remains a less coherent understanding across these new fields and topics of what digital innovation is, how it differs from earlier industrial age innovations, and how one should interpret and conceive it from each discipline's and function's viewpoint. In particular, we remain confused and overwhelmed as to how the dizzying variety of emerging research questions and new interests related to digital innovation expressed in different fields can in toto help us understand digital innovation as a unique, unprecedented, coherent, and dynamic phenomenon. Adding to this confusion, a wide range of terms related to digital innovation have been put forward in the different fields resulting in challenges to triangulate the key concepts and the underlying issues. For example, with relatively little effort we can find references to digital innovation, digital transformation, digitization, digitalization, post-industrial era, or the fourth industrial revolution. Each such term sheds light on and anticipates slightly different aspects of what is happening and emphasizes different ways of looking at the underlying drivers. In order to properly frame and understand this important and pervasive phenomenon that is now rapidly shaping the global economic system of the twenty-first century, each scholarly community needs to be more reflexive in its attempt to grasp the phenomenon it is facing in a more holistic and transdisciplinary way. 
There is a critical need for broadening the horizon of inquiry, questioning and testing established categories and ways of defining the focal phenomena, and seeking better interfaces with other disciplines. The old metaphor of ten men touching an elephant applies here. To understand better what this object is they need to collaborate and reconcile and merge their differences. This calls for participating in an open and genuine transdisciplinary dialogue whereby the different scholarly communities can jointly identify the foundational concepts (that would enable transdisciplinary triangulation and dialogue) and search for answers to questions that deal with the nature of this novel phenomenon. To our knowledge, there is currently no single forum that brings together scholars from multiple fields who share an interest in investigating this important phenomenon.

Further, as digital innovation now cuts across industries and breaks down old industrial organization, it is also of significant importance to study the associated individual, team, firm, and industry level interactions, i.e. to view digital innovation as a dynamic complex (sociotechnical) system, recognizing the constantly shifting and new boundaries of firms and other entities. This, in turn, calls for more orchestrated efforts to analyze individual, team, firm, community, and industry level changes simultaneously (Nambisan, Wright, \& Feldman, 2019; Yoo et al., 2010a; Yoo, Boland, Lyytinen, \& Majchrzak, 2012), and more importantly, to analyze their dynamics holistically, as firm-level innovation increasingly rests on industry-wide infrastructures while firms' innovation efforts contribute to building such infrastructures. All of this happens in the context of open communities, individual and user-led innovation, and new forms of collaborating and competing at the industry level. As such, this also means that some of the core constructs such as firm, industry, market, product, resource, complementarity, and contracts are changing. Some of these changes that we see are fundamentally new, while other changes are simply derivatives of those fundamental changes. One must separate these two different forms of changes in order to understand what are qualitatively different and new, and what feels like different but fundamentally are the same.

Overall, the goal of such transdisciplinary effort would be to better understand the nature, process, and consequences of digital innovation - both as a holistic system that spans individual, firm, and industry levels as well as a broader societal phenomenon. This has implications far beyond the traditional business disciplines and functions. As noted previously, the attempts to engage in such dialogues and build common understanding of this phenomenon have been few and far between and this forms the primary motivation for this Handbook. While such a dialogue cannot happen overnight, offering a vehicle for facilitating it is an important first step in that direction. In this introductory chapter, we first briefly consider some of the conceptual foundations of digital innovation and then discuss how this Handbook came about, its organization, and the various contributions.

\section{THEORIES AND CONCEPTUAL FOUNDATIONS OF DIGITAL INNOVATION}

Over the last 20 years, organizational and information systems research has significantly increased our understanding of the impacts of digital technologies in organizations and society (Fulk \& DeSanctis, 1995; Zammuto, Griffith, Majchrzak, Dougherty, \& Faraj, 2007). Most of these studies, however, have been confined to the uses of a single information technology solution in the context of inter- or intra-organizational processes and administrative structures. 
Most of them have focused on the purposes of either automating or informating of such processes (Orlikowski \& Barley, 2001; Zuboff, 1988). In recent years, especially during the last decade, a new breed of innovations enabled by digital technologies has emerged. This new breed is largely characterized by the inherent and seemingly unbounded generativity of digital technology (e.g. McAfee \& Brynjolfsson, 2017; Nambisan, 2017; Nambisan et al., 2019; Parker, Van Alstyne, \& Choudary, 2016; Yoo et al., 2010a, 2012) which has resulted in the pervasive penetration of digital technology uses in all spheres of firms' operations including products, services, and customer experience (e.g. Porter \& Heppelmann, 2014).

So, what is the unique nature of digital, or, in academic parlance, the ontology of digital that makes it so different from previous physical materials and contexts of innovation and produces this power of generativity and penetration? Over the last ten years or so, a growing stream of insightful work has focused on this question - see for example, Faulkner and Runde (2013, 2019), Kallinikos et al. (2013), Tilson, Lyytinen, and Sørensen (2010), and Yoo et al. (2010a, 2012) - as scholars have tried to develop a deeper understanding of how the digital environment has changed and its implications. In the context of this book, we next offer a short synthesis of these views and analyses so as to unpack the unique ontology of "digital" and to help the reader to contextualize and interpret the arguments made in this book. More broadly, we aim to build an initial understanding of and justification for the ongoing context shifting, i.e. how and why "digital innovation" differs from "general innovation" and to what extent digital technologies have the capacity to acquire properties which promote new kind of innovation agency, process, and outcomes.

In general, in any account of technology-based innovation in a social context, we need to distinguish between a technological object with specific properties and the affordances that it provides to social actors involved in a specific context, i.e. the ability to do things in the setting which they would not be able to do without the technology object being present. For instance, a rifle has the property of leveraging bullets in high speed, force and accuracy enabling the affordance of "shooting." Without a rifle, such an affordance is not possible. Initially, objects and their properties connect over time to social actors, sometimes the same object connecting to different types of actors (such as a hunter, a policeman, a soldier, a gang member in the case of the rifle). Those actors shape relationships with other actors, and in turn, influence and evolve the agency of the set actors, creating emergent system properties (such as competition between hunters, and so on) leading to social innovations. Similarly, the learning algorithms that operate autonomously in current AI systems enable new types of agency for high frequency traders in investment firms as the algorithms learn and execute faster than humans and at such scale, that the idea of equities themselves will change along the way (Faraj, Pachidi, $\&$ Sayegh, 2018). This results in innovations related to how the trading is organized and how markets are structured and operate.

Generally, we note three essential aspects of "digital" that characterize its driving logic as an impetus for innovation: (1) agential core; (2) semiotic binding; and (3) ontological reversal.

Agential core: A focus on digital innovation reflects the current need to account for the multiple, expanding, and changing properties of digital technologies (cloud, massive data marts, high speed networks, mobile and sensor technologies, and powerful new algorithms, to name a few). These highly mutable and readily recombinable properties now change the role and relationships of the technology in social and business settings, transforming the agency that the social and the technical elements jointly exhibit as emerging sociotechnical systems (Tilson et al., 2010; Yoo et al., 2010a). To put it in another way: acting in current social and business set- 
tings has become fundamentally different as the scope and range of affordances of digital technologies have changed and are continually changing, forming new types of joint agency which cannot be accounted by existing theories of technology use and innovation. For example, in the classic information systems research, IT was conceived as an object with distinct set of technical properties and capabilities, such as a PC, user interface, networks, and mainframe backend having database and transaction capabilities. These properties and capabilities are either known or knowable ex ante the use of the object. These objects - through their properties and capabilities - gave involved social actors, such as individuals, teams, or organizations, the ability to (inter-)act with scale, scope, and efficiency. In the "digital innovation" story that is emerging in the information systems field, social actors are surrounded by and constantly interacting with (and through) the ubiquitously present digital technologies - such as mobile and wearable tools, Web services powered by broadband and APIs, sensors embedded in ordinary physical objects and environments, artificial intelligence algorithms and models, and cloud infrastructure - all of which confer more generic and fundamental properties such as editability, addressability, senseability, communicability, memorizeability, traceability, and associability (Yoo, 2010). These properties and their associated uses are accompanied by deep transformations in business logic, behavior, and outcomes, and in the very meaning of products and services themselves (Henfridsson \& Bygstad, 2013; Chanias, Myers, \& Hess, 2019; Nambisan, 2017; Vial, 2019; Yoo, 2010). Combined with the global infrastructure and user communities, re-programmability, recombinability, and self-referentiality make digital technologies highly mutable, dynamic, and autonomous. Therefore, the properties and capabilities of "digital innovation" may not be fully known or knowable ex ante. In the classic story of IT, we assume that a specific technological "box" does something for the actor; in the "digital innovation" story, digital does first what IT can do, but it also enhances the flexibility and speed of actors to improve or create new outcomes (in unpredictable ways) through generativity (Fürstenau, Baiyere, \& Kliewer, 2019; Lyytinen, Sørensen, \& Tilson, 2018).

Semiotic binding: All digital innovations are founded on varied digital representations (either in behavior or in data). These representations have little value unless they are contextualized to a machine and/or social setting. In a social setting, data and related code-based behaviors need to be accounted as something meaningful in the setting for actors to use - such as a 'like' in Facebook, 'a trade' in high frequency trading systems, or a 'game move' in Go for a deep learning algorithm playing Go. The quality and nature of such semiotic bindings is not the same as a physical binding, for example, between a car model and its multiple instances in a production line enabling related economies of scale to emerge while innovating with industrial technologies. Semiotic bindings are institutionally and socially mediated and therefore can only be "socially" approximate-while the bindings change they will also expand related social institutions and related innovations (Oshri, Henfridsson, \& Kotlarsky, 2018). This "unaccounted" or "indeterminate" nature of semiotic binding enables constant innovation and repurposing in the use of digital technologies. Actors in different contexts will invent alternative ways of binding the code and data (and expanding it) to new social settings (Hukal \& Henfridsson, 2018). Such digitally mediated interactions and related bindings are now available in every walk of life.

Ontological reversal: With traditional information systems, all digital representations were the reflection of the physical world that exist a priori. IT objects (be it data or algorithm) represent an existing and expected reality. But increasingly, with "digital innovation," digital technologies shape the reality. Baskerville and colleagues (Baskerville, Myers, \& Yoo, 2020) refer 
to it as ontological reversal. In observing the ontological reversal between signs as reference and the reality as referent, Jean Baudrillard (1994) observes "a liquidation of all referential" as the key characteristic of our contemporary technological society, noting that "[s]imulation is no longer that of a territory, a referential being or a substance. It is the generation by models of a real without origin or reality ... It is no longer a question of imitation, nor of reduplication, nor even of parody. It is rather a question of substituting signs of the real for the real itself" (pp. 1-2). With ontological reversal, the non-physical digital objects are not just as real as physical objects; they are more real. Prior to 2008, an air ticket sale produced a physical ticket and a digital record of the transaction (as a sign of the reality) was stored in the airline's data center as evidence of the transaction. Since 2008 when 100 percent of the airline ticketing process became electronic, physical tickets are no longer produced. The real tickets exist in the cloud. When a passenger needs a physical evidence of the real, yet non-physical, ticket, she can reproduce a physical copy of the non-physical real. The ontology of the physical and digital has been reversed. With the ontological reversal, there is a temporal reversal in the way products are produced. The digital version is produced first, the physical version is produced when and where it makes sense.

Overall, these three features and the ensuing generativity have resulted in the continued emergence of digitally enabled novel products including smartphones, smart buildings, and smart cars that interact with global digital infrastructures such as global wireless networks and the Internet. We also have novel means of productions and distributions in the firm of 3D printing, virtual reality, augmented reality, and gig or shared economy. Digitalized products also evolve at faster pace due to novel recombinations of existing digital artifacts and their capabilities thanks to semiotic binding (Arthur, 2009; Yoo, 2012). This relentless evolution of products and services simultaneously triggers reverberating changes in the organizations that participate, engage in, and support such innovations challenging received theories and empirical analyses of the nature of innovation, strategy, and foundations of competition (Benner \& Tushman, 2015; Nambisan, 2017; Nambisan et al., 2017; Yoo, Lyytinen, Thummadi, \& Weiss, 2010b).

Given the emergence of a new breed of increasingly unbounded and generative digital innovations, we posit that we are not just looking at yet another radical product innovation. We are facing a new kind of innovation phenomenon, where the origins, enablers, and targets of innovative activities are increasingly shaped by digital environments which share the unique features of digitizing and digital technologies (Kallinikos et al., 2013; Nambisan, 2017; Nambisan et al., 2017; Yoo et al., 2010a, 2012). This creates a need to carefully consider the repercussions of the very nature of digital technology on explaining innovation in any field or discipline when studying digital innovations. By doing so, scholars from diverse fields will be better positioned to extend, revise, and test their received innovation theories and validate the emerging broader organization and innovation theories in the context of pervasive digitalization.

\section{HOW THIS HANDBOOK CAME ABOUT (AND WHO IT IS MEANT FOR)}

In the Fall of 2018, the first author received an invitation from Edward Elgar Publishing to edit a new Handbook on Digital Innovation. An initial examination indicated that despite 
the number of articles on digital innovation published in various journals, there had been no concerted effort made to bring together ideas and perspectives from different fields in ways that would facilitate development of cumulative knowledge. A Handbook focused on sharing diverse disciplinary perspectives of digital innovation-i.e. one that moves beyond discipline-specific approaches to understanding digital innovation-could potentially facilitate more transdisciplinary conceptual and empirical work in this area. To this end, we invited contributions from scholars in different fields - ranging from business and economics to engineering and science - to share their ideas, concepts, and perspectives on digital innovation covering technology capabilities, innovation organization and processes, firm-level organization and strategy, individual level behaviors and use, and broader industry and societal implications.

We believe (and hope) that our effort here will also contribute to a longer-term goal of building an eclectic and open community of scholars interested in studying diverse and multifaceted aspects of digital innovation. Indeed, our broader goals in this initiative are threefold:

1. To create a holistic, transdisciplinary framework of digital innovation that offers a coherent theoretical language to investigate emerging phenomena of digital innovation in different fields and industries.

2. To create a generic model of digital innovation at the firm level that covers technical, organizational, economic, and social dimensions.

3. To create a generic model of digital innovation and associated empirical tools to study the proliferation of digital innovation at the industry level so that scholars can compare and contrast different industries.

Importantly, this Handbook is not targeted at researchers alone. The perspectives, ideas, and concepts discussed here should also be of much interest to thoughtful practitioners as it may help reveal potential linkages across fields along with their practice implications.

\section{HOW THIS HANDBOOK IS ORGANIZED}

Given our broader objective of promoting transdisciplinary dialogue on digital innovation, we have tried to bring together diverse voices and perspectives in this Handbook. The Handbook is organized into multiple sections, each of which is focused on a common theme/topic and includes a brief introduction by a section editor (an invited scholar) and the chapters related to that theme. The section introduction is not meant as a summary or critique of the chapters in that section; rather, it incorporates a reflection of the section editor on the topic and as such it is meant to be integrative and thought-provoking.

Part II (which follows this introductory chapter) is focused on the Foundations of Digital Innovation. In his introduction to this section, Joel Cutcher-Gershenfeld highlights the fundamental challenges that have emerged in the post-industrial digital era regarding the organizational and institutional arrangements that best align with the associated digital technologies and the needs of society. He also calls for more careful and detailed investigation of both the micro- and macro-level issues, and importantly, for deriving valuable policy prescriptions for the future. Following that, the section includes four chapters that raise fundamental issues related to the nature of digital innovation and their implications. Majchrzak and Griffith (Chapter 2, "The new wave of digital innovation: the need for a theory of sociotechnical 
self-orchestration") highlight the potential for digital technologies to enable, constrain, or shape the nature of innovation as a collective action and propose a new theoretical conceptualization, sociotechnical self-orchestration, to explain the actions of modern work in organizations. Jarvenpaa and her colleagues (Chapter 3, "Digital innovation and entrepreneurship in and around institutional voids: the case of Fundación Cardiovascular (FCV) in Colombia") focus on digital innovation in the context of emerging economies, and in particular, examine institutional voids - the absence or under-development of market and nonmarket institutionsand chronicle the activities of an entrepreneurial firm in Northeastern Colombia that was able to innovate with digital technologies despite these voids. Markus and Nan (Chapter 4, "Theorizing the connections between digital innovations and societal transformation: learning from the case of M-Pesa in Kenya") apply qualitative comparative analysis to analyze the connections between digital innovation and societal transformation and derive a set of theoretical insights that are "contingently general." In the final chapter of this section (Chapter 5; "Agile development as the root metaphor for strategy in digital innovation"), Berente proposes agile development - which emphasizes user-centered design, continuous experimentation, responsiveness, and fast cycle times - as the root metaphor for framing and analyzing organizational strategy in the digital era.

Part III is focused on Digital Platforms, Ecosystems, and Entrepreneurship. In her introduction to this section, Annabelle Gawer differentiates between innovation platforms and transaction platforms and identifies several challenges that firms face in both of these contexts (including curbing the power of the platform leader) and the ensuing issues for future research. The three chapters that follow this consider different aspects of platforms and ecosystems and how they shape innovation and entrepreneurship. Specifically, Autio and Thomas (Chapter 6, "Value co-creation in ecosystems: insights and research promise from three disciplinary perspectives") review the research on ecosystems in three different areas (marketing, strategy, IS) and derive a set of insights for future research and practice. Nickerson (Chapter 7, "Remixing systems: collective design through modification") examines the relatively novel concept of "remixing" and presents a critique of existing scholarship in this area. Henfridsson (Chapter 8, "Scaling digital enterprises") discusses how the nature and scope of venture scaling has been transformed due to digital technologies and the implications for future research.

Part IV focuses on Digital Innovation, Business Models, and Value Creation, i.e. on how digital technologies have changed the nature of value creation and the structure of business models. In his introduction, Varun Grover highlights some of the fundamental differences between information technology (IT) and "digital" and enumerates the implications of that for how firms (and other entities) create, deliver, and appropriate value. In Chapter 9 ("Data and value"), Alaimo and her colleagues consider the nature and structure of the digital value chain and identify some of the important implications for future research. Velu (Chapter 10, "Business model cohesiveness scorecard: implications of digitization for business model innovation") develops the notion of a business model cohesiveness scorecard and discusses the implications of digitization for business model innovation. Seidel and Berente (Chapter 11, "Automate, informate, and generate: affordance primitives of smart devices and the Internet of Things") adopt a technology affordance perspective to examine the business implications of the Internet of Things (IoT).

Part $\mathbf{V}$ is focused on Digital Innovation and Future of Work. In his introduction to this section, Paul Courant notes that as in so many issues involving the interactions between information technology and society, the details and contexts will matter if we want to understand 
how digital innovation shapes the nature of work. In other words, efforts to generalize and state that digital innovations will reduce the number of jobs or lower their quality (or vice versa) will not be very useful. King and Grudin (Chapter 12, "Prolegomena on digital innovation and jobs") review the extant scholarship on digitization and work and note why the lack of adoption of a more holistic (or systemic) lens has led to the failure to generate a nuanced understanding of the implications of digitization for productivity and future of work. Malhotra (Chapter 13; "Making the one-sided gig economy really two-sided: implications for future of work") uses data from an online community of Uber drivers to identify and analyze the myriad issues related to work and firm-employee relationships in the sharing economy.

Part VI focuses on Digital Innovation and Application Domains. In his introduction, Kenneth Loparo highlights the significant opportunities offered by the Internet of Things - in sectors as varied as consumer products, healthcare, banking and finance, manufacturing, energy, transportation and mobility, and education - and more importantly, the challenges they present in the form of security, privacy, etc. This section has two chapters, written by scholars from engineering and medicine respectively. Kulathinal and his colleagues (Chapter 14, "The bits and bytes of biology: digitalization fuels an emerging generative platform for biological innovation") consider how digital technologies have revolutionized the broad field of biology, and more specifically, how digitalization has provided a common platform for researchers from different areas of biology/medicine to understand life. In Chapter 15 ("Innovations in microrobotics and their implications in a digital world"), Rogowski and colleagues consider the innovations unleashed by digital technologies in the field of microrobotics and discuss their implications.

In the concluding chapter (Chapter 16, "A transdisciplinary research agenda for digital innovation: key themes and directions for future research"), we identify some important questions and themes that emerge from the different chapters. These questions and themes portray both the promise and potential for future research in digital innovation as well as the challenges in pursuing them. As we noted previously, in developing this Handbook, we did not set out to answer questions related to digital innovation; rather we hope that it will help raise important questions that cut across different fields and disciplines and present an agenda for future research. Our effort in this final chapter is to articulate such a research agenda.

\section{CONCLUSION}

Digital innovation influences every aspect of our lives in this increasingly digitalized world. Much of our everyday activities are shaped and influenced by various digital services. Therefore, firms that pursue new forms of digital innovations must think about how their products and services affect their users and what are the long- and short-term social, economic, and cultural consequences. Indeed, recent incidents related to Uber, Facebook, and other digital companies suggest the far-reaching implications (including at the global level) of digital innovation pursued by individual firms. At the same time, we don't seem to have a shared set of concepts, constructs, and frameworks to carefully analyze, examine, and understand these implications. Importantly, as we noted previously, such a shared set of concepts related to digital innovation will inherently need to be transdisciplinary. The ideas and concepts presented in this Handbook will hopefully serve as the first step in this direction. 
Specifically, by bringing together a diverse set of scholars and their views on digital innovation, we believe it creates a rare opportunity to exchange and validate their unique perspectives on digital innovation and make novel connections that will foster new forms of theory and empirics that were not previously possible. Further, we also hope that together the chapters in this Handbook will contribute to developing a common vocabulary that can provide coherent guidance towards research exchanges on digital innovation across distinct intellectual and disciplinary boundaries. This will enable scholars in different fields to build a cumulative intellectual tradition on digital innovations beyond their own field. And, more broadly, we believe the chapters allow for identifying an important set of questions related to digital innovation - questions that will help set the agenda for the ongoing debate on digital innovation and digital transformation in ways that could inform not only firm-level strategies but policy decisions and science-focused investments as well.

\section{ACKNOWLEDGEMENTS}

The Digital Innovation workshop and the materials in Chapters 1, 14 and 16 are in part supported by National Science Foundation (Grant \# 1447670) and the Ministry of Education of the Republic of Korea and the National Research Foundation of Korea (NRF-2018S1A3A2075114). Any opinions, findings, and conclusions or recommendations expressed in this material are those of the author(s) and do not necessarily reflect the views of the funding organizations.

\section{REFERENCES}

Arthur, W. B. (2009). The nature of technology: What it is and how it evolves. New York: Simon \& Schuster.

Baskerville, R., Myers, M., \& Yoo, Y. (2020). Digital first: The ontological reversal and new challenges of IS researching. MIS Quarterly (forthcoming).

Baudrillard, J. (1994). Simulacra and simulation. Ann Arbor, MI: University of Michigan Press.

Benner, M. J., \& Tushman, M. L. (2015). Reflections on the 2013 Decade Award-“Exploitation, exploration, and process management: The productivity dilemma revisited" ten years later. Academy of Management Review, 40(4), 497-514.

Chanias, S., Myers, M. D., \& Hess, T. (2019). Digital transformation strategy making in pre-digital organizations: The case of a financial services provider. The Journal of Strategic Information Systems, 28(1), 17-33.

Eaton, B. D., Elaluf-Calderwood, S. M., Sørensen, C., \& Yoo, Y. (2011). Structural narrative analysis as a means to unfold the paradox of control and generativity that lies within mobile platforms. Proceedings of the 2011 10th International Conference on Mobile Business, ICMB 2011. https://doi .org/10.1109/ICMB.2011.16.

Faraj, S., Pachidi, S., \& Sayegh, K. (2018). Working and organizing in the age of the learning algorithm. Information and Organization, 28(1), 62-70.

Faulkner, P., \& Runde, J. (2013). Technological objects, social positions, and the transformational model of social activity. MIS Quarterly, 37(3), 803-818.

Faulkner, P., \& Runde, J. (2019). Theorizing the digital object. MIS Quarterly, 43(4), 1279-1302.

Fulk, J., \& DeSanctis, G. (1995). Electronic communication and changing organizational forms. Organization Science, 6(4), 337-349.

Fürstenau, D., Baiyere, A., \& Kliewer, N. (2019). A dynamic model of embeddedness in digital infrastructures. Information Systems Research, 30(4). 
Henfridsson, O., \& Bygstad, B. (2013). The generative mechanisms of digital infrastructure evolution. MIS Quarterly, 37(3), 907-931.

Hukal, P., \& Henfridsson, O. (2018). Digital innovation: A definition and integrated perspective. In D. Galliers \& K. Stein (Eds.), The Routledge companion to management information systems (pp. 360-369). New York: Routledge.

Kallinikos, J., Aaltonen, A., \& Marton, A. (2013). The ambivalent ontology of digital artifacts. MIS Quarterly, 37(2), 357-370.

Lyytinen, K., Sørensen, C., \& Tilson, D. (2018). Generativity in digital infrastructures: A research note. In D. Galliers \& K. Stein (Eds.), The Routledge companion to management information systems (pp. 253-275). New York: Routledge.

McAfee, A., \& Brynjolfsson, E. (2017). Machine, platform, crowd: Harnessing our digital future. New York: W. W. Norton.

Nambisan, S. (2017). Digital entrepreneurship: Toward a digital technology perspective of entrepreneurship. Entrepreneurship Theory and Practice, 41(6), 1029-1055.

Nambisan, S., Lyytinen, K., Majchrzak, A., \& Song, M. (2017). Digital innovation management: Reinventing innovation management research in a digital world. MIS Quarterly, 41(1), 223-238.

Nambisan, S., Wright, M., \& Feldman, M. (2019). The digital transformation of innovation and entrepreneurship: Progress, challenges and key themes. Research Policy, 48(8), 103773.

Orlikowski, W. J., \& Barley, S. R. (2001). Technology and institutions: What can research on information technology and research on organizations learn from each other? MIS Quarterly, 25(2), 145-165.

Oshri, I., Henfridsson, O., \& Kotlarsky, J. (2018). Re-representation as work design in outsourcing: A semiotic view. MIS Quarterly, 42(1), 1-23.

Parker, G. G., Van Alstyne, M. W., \& Choudary, S. P. (2016). Platform revolution: How networked markets are transforming the economy. New York: W. W. Norton.

Porter, M. E., \& Heppelmann, J. E. (2014). How smart, connected products are transforming competition. Harvard Business Review, 92(11), 64-88.

Tilson, D., Lyytinen, K., \& Sørensen, C. (2010). Digital infrastructures: The missing IS research agenda. Information Systems Research, 21(4), 748-759.

Vial, G. (2019). Understanding digital transformation: A review and a research agenda. The Journal of Strategic Information Systems, 28(2), 118-144.

Yoo, Y. (2010). Computing in everyday life: A call for research on experiential computing. MIS Quarterly, 34(2), 213-231.

Yoo, Y. (2012). Digital materiality and the emergence of an evolutionary science of the artificial. In P. M. Leonardi, B. A. Nardi, \& J. Kallinikos (Eds.), Materiality and organizing: Social interaction in a technological world (pp. 134-154). Oxford: Oxford University Press.

Yoo, Y., Boland Jr., R. J., Lyytinen, K., \& Majchrzak, A. (2012). Organizing for innovation in the digitized world. Organization Science, 23(5), 1398-1408.

Yoo, Y., Henfridsson, O., \& Lyytinen, K. (2010a). The new organizing logic of digital innovation: An agenda for information systems research. Information Systems Research, 21(4), 724-735.

Yoo, Y., Lyytinen, K., Thummadi, B. V., \& Weiss, A. (2010b). Unbounded innovation with digitalization: A case of digital camera. Presentation at the Annual Meeting of the Academy of Management.

Zammuto, R. F., Griffith, T. L., Majchrzak, A., Dougherty, D. J., \& Faraj, S. (2007). Information technology and the changing fabric of organization. Organization Science, 18(5), 749-762.

Zuboff, S. (1988). In the age of the smart machine. New York: Basic Books. 